\title{
Effect of Nanoclay on Natural Rubber Microstructure
}

Javier Carretero-González, ${ }^{* \dagger}$ Haris Retsos, ${ }^{\ddagger}$ Raquel Verdejo, ${ }^{\dagger}$ Shigeyuki Toki, ${ }^{\S}$

Benjamin S. Hsiao, ${ }^{\S}$ Emmanuel P. Giannelis ${ }^{\ddagger}$, Miguel A. López-Manchado, ${ }^{*} \dagger$

Institute of Polymer Science and Technology, CSIC, Madrid 28006, Spain

Department of Material Science and Engineering, Cornell University, Ithaca, New York 14853

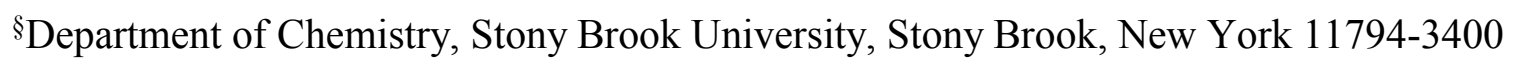

*Address correspondence to: jcarretero@ictp.csic.es or 1manchado@ictp.csic.es. 


\begin{abstract}
The inclusion of highly anisotropic clay nanoparticles (nanoclays) in cross-linked natural rubber $(\mathrm{NR})$ provides a more homogeneous distributed network structure and induces an early onset as well as enhancement of crystallization under uniaxial deformation. The molecular structure of the polymer network and its morphological changes during deformation were characterized by using broadband dielectric spectroscopy and in-situ synchrotron wide-angle Xray diffraction, respectively. It was found that the presence of nanoclay introduces a dual crystallization mechanism due to the alignment of nanoparticles during stretching. The improved properties in NR-nanoclay nanocomposites can be attributed to both microstructural and to morphological changes induced by nanoclay; as well as to the nanoclay mobility in the NR matrix during crystallization. The interplay of these factors during deformation contributes to the formation of a super-network structure containing cross-linked chemical chains, nanofiller and crystallizable networks with similar length scales.
\end{abstract}

Keywords: nanoclay, natural rubber, nanocomposites, dielectric spectroscopy, strain-induced crystallization. 


\section{Introduction}

Natural rubber (NR, the major component is cis-polyisoprene) is one of the most fascinating and important industrial polymers among many engineering plastics. ${ }^{1}$ The principal reasons for the versatility of NR are its high green strength, which is in turn due to the presence of non-rubber components (phospholipids and proteins) ${ }^{2}$ and its ability to crystallize upon stretching in unvulcanized $^{3}$ and vulcanized state, ${ }^{4}$ which is ultimately determined from the non-rubber components and the high stereoregularity ${ }^{5}$ of NR.

A common practice to enhance the mechanical properties of NR is the introduction of chemical crosslinks as well as the addition of finely divided particulates, typically carbon black or silica. ${ }^{6} \mathrm{~A}$ minimum of $20-30 \mathrm{wt} \%$ of conventional filler is required to attain optimal mechanical properties, but this high concentration reduces the processability and increases the weight of the final product. The continuous demand for new, low-cost, low-weight rubber composites with improved properties represents a challenge in the polymer industry. ${ }^{7}$ Polymer nanocomposites offer the possibility for new alternatives. ${ }^{8}$ The inclusion of nanosized particles, in particular layered silicates (nanoclays), ${ }^{9}$ enables the enhancement of properties in polymers with even at small amounts of fillers, a feature not possessed by conventional composites. This was in fact the case for NR-nanoclay nanocomposites. It was found that the inclusion of $10 \mathrm{phr}$ (parts per hundred of rubber) nanoclay greatly improves the mechanical properties of NR compounds over the conventionally filled systems. ${ }^{10}$ Nevertheless, the mechanism of the reinforcement is still poorly understood. For example, what does it make NR-nanoclay materials stronger than conventionally filled rubbers without scarifying properties like hardness, resilience or compression set? According to the molecular models of conventional rubber compounds, for filled and crystallizable vulcanized rubbers, the main reason for the rise in the tensile strength at 
low deformations (below crystallization) has been considered as the formation of additional crosslinks resulted from the filler-elastomer interactions due to the presence of fillers. Regarding the effect of nanoclay, we note that for the same weight/volume fraction of filler, the nanosized platelets would lead to four-six orders of magnitude more particles per volume than classic mineral fillers. ${ }^{11}$ A large amount of surface area will be exposed to the rubber molecules leading to a huge interfacial volume around the nanofillers.

However, several points must be considered in order to better understand the differences between conventional and nanoclay-filled NR systems. Conventionally filled NR contains rigid aggregates of silica or carbon black particles, which can lead to a filler network with different level of aggregation. ${ }^{12}$ Interactions between these micron sized particles forming clusters can cause a considerable change in viscoelastic properties. ${ }^{13}$ However, this effect is absent in NRnanoclay systems. The filler network in NR nanocomposites is arranged in small groups of finely dispersed clay tactoids (containing $\sim 10$ layers). These tactoids are largely isolated and separated each other by $\sim 10-50 \mathrm{~nm}$ without forming any rigid filler framework with fractal structure. This is due to the high level of dispersion nanoclay in the nanocomposites. Breakdown or reconstitution of the nanoclay network (Payne effect) ${ }^{14}$ by increasing the strain amplitude have not been observed in NR nanocomposites with clay loadings below $30 \mathrm{phr}^{15}$ Therefore, the high elastic modulus and the low hysteresis observed in NR-nanoclay nanocomposites in the low strain regime might be due mainly to the hydrodynamic effect and the interactions between nanoclay and polymer.

Another important issue, mentioned above, is the assumption of the strength increase in NRnanocomposite has often been attributed to rubber-filler interactions. ${ }^{16}$ Such an assumption implies that the ability of the filler to toughen the matrix at any strain is independent of the 
thermodynamic state of the polymer matrix. Several experimental and theoretical studies have challenged the notion that the polymer-filler interactions are the only factor that is responsible for reinforcing the polymer nanocomposites. ${ }^{17}$ It is conceivable that some other energy dissipation mechanism, resulting from the mobility of the nanoparticle that can act as temporary cross-links between polymer chains and nanoparticles, can also hinder the failure during deformation.

The above hypothesis is hard to verify because it is difficult to investigate NR-nanoclay nanocomposites under deformation without the induction of crystallization. Generally, straininduced crystallization (SIC) occurs at strains beyond a critical value. The addition of micron size fillers to NR has been thought of as superimposing another level of filler network at the larger scale in the system. ${ }^{18}$ But, this may not be the case for NR nanocomposites and some interesting questions need to be addressed: (1) Will the dispersed nanoparticles induce a filler network structure with a similar length scale than the chemically crosslinked rubber chains? (2) How would the plate-like particles affect the crystallization? To answer these questions, it is necessary to first understand the effect of nanoclay on the final distribution of the network topology (chemical and physical) and the possible network defects. It is well known that the effective number of network imperfections such as dangling, and loops in unfilled NR networks increases by cross-linking as a consequence of heterogeneous distribution of the crosslink junctions ${ }^{19}$ and a broad distribution of chain length between the junction points. ${ }^{20}$ Both factors will greatly impact the orientation of the polymer chains during deformation and consequently the final crystalline fraction. Thus network imperfections will not alter the property resulted from the chain orientation due to SIC. ${ }^{21}$ In contrast, the dense network region (highly cross-linked) would favor the molecular orientation of the chains at the early stages of deformation. ${ }^{22}$ However, the induced crystallization also retards the process of nucleation due to the reduced segment mobility in these 
regions. ${ }^{23}$ For filled-NR with conventional fillers, several studies ${ }^{24}$ have concluded that although the presence of fillers promotes crystallization, it does not increase the overall crystalline content in comparison with the unfilled systems. This effect could be due to the low volume fraction (0.1) necessary for the aggregation of fillers. ${ }^{25}$ In other words, the conventionally filled rubber compounds might possess a non-homogeneous dispersion of fillers due to the high amount of particles used for reinforcement, approximately $40-60 \mathrm{phr}$. In addition, the micron size fillers could behave as heterogeneities preventing the rubber chain from aligning and crystallizing, even though the presence of filler could promote strain-induced crystallization. It has been reported that the micron size particles, when they do not interact strongly with the matrix, can effectively decrease the local stress and hinder SIC. ${ }^{26}$ Contrary to this observation, a remarkable enhancement of SIC in vulcanized NR nanocomposite under uniaxial stretching due to the presence of nanoclay has recently been reported by Carretero-González et al. ${ }^{27}$

In this work, we present experimental evidence of a more homogeneous NR network microstructure after the addition of nanoclay. The molecular ordering of the polymer network was evaluated by dielectric relaxation spectroscopy. The behavior of SIC was followed in-situ by synchrotron radiation. It was found that platelets with a lateral size sufficiently large result in a rapid crystallization rate and different morphology when compared with the system containing small disc size or lower aspect ratio. The results indicate that the addition of nanoclay particles to NR leads to a relatively "homogeneous" distribution of networks containing several different components. In addition, the large interfacial surfaces introduced by nanoclay facilitate the overall chain orientation during deformation resulting in an increase in final crystallite fraction. 


\section{Experimental}

Materials. NR (CV60) sample with a Mooney viscosity (ML (1+4)) at $100{ }^{\circ} \mathrm{C}$ of 60 was supplied by Malaysian Rubber, Berhad, Malaysia. The layered silicates employed in this study were: a naturally occurring sodium montmorillonite $\left(\mathrm{Na}^{+}-\mathrm{MMT}\right)$, an organically modified montmorillonite (O-MMT) and an organically modified synthetic hectorite: laponite clay $(\mathrm{O}-$ LAP). All of the clay samples were provided by Southern Clays Products. The main characteristics of the clays are reported in Table 1.

Materials Preparation. The formulation of natural rubber compounds expressed as parts per hundred of rubber (phr) is as follows: sulfur (2.5), ZnO (5), stearic acid (1), MBTS (Benzothiazyl disulfide) (1), antioxidant PBN (Phenyl beta napthyl amine) (1) and layered silicate (15). The nanocomposite samples were prepared in an open two-roll laboratory mixing mill at room temperature. Vulcanization was carried out in an electrically heated hydraulic press at $150{ }^{\circ} \mathrm{C}$ using the optimum cure time $\left(t_{90}\right)$ previously determined with a rubber process analyzer (RPA Alpha Technologies). The samples are referred as NR/y, where y corresponds to the type of clay used.

Characterization. $X$-Ray diffraction was performed in a $\theta-\theta$ diffractometer with an integrated germanium detector, using a $\mathrm{CuK} \alpha$ source with a wavelength of $1.54 \AA$ and a scan rate of $2^{\circ} \mathrm{min}^{-}$

1. SAXS experiments were performed on Bruker AXS Nanostar $(\mathrm{CuK} \alpha 1.54 \AA$ ) operated at 40 $\mathrm{KV}$ and $40 \mathrm{~mA}$ in a transmission mode. The dispersion and morphology of the clay nanoparticles in the rubber matrix was determined through transmission electron microscopy (TEM), using a Technai T12 TEM operated at an accelerating voltage of $120 \mathrm{kV}$. TEM samples with $\sim 40 \mathrm{~nm}$ thickness were prepared by sectioning at $-160^{\circ} \mathrm{C}$ using a Leica Ultracut UCT cryoultramicrotome 
with a diamond knife. The degree of curing was studied by a TA Instrument Q1000 DSC. A scanning of $4{ }^{\circ} \mathrm{C} / \mathrm{min}$ from $-100{ }^{\circ} \mathrm{C}$ to $165{ }^{\circ} \mathrm{C}$ and a heat/cool/heat cycle under nitrogen atmosphere was employed to eliminate any thermal history in the sample. Dynamic-mechanical properties in the range of -150 to $150{ }^{\circ} \mathrm{C}$ were obtained using a TA instrument Q800 DMA at 1 $\mathrm{Hz}$ and $2{ }^{\circ} \mathrm{C} / \mathrm{min}$ heating rate. The average mass of network chains $M_{c}$ was determined on the basis of equilibrium swelling experiments $(\sim 48 \mathrm{~h})$ using toluene at $30^{\circ} \mathrm{C}$ by application of the modified Flory-Rehner equation. ${ }^{28}$

$$
-\ln \left(1-\phi_{r}\right)-\phi_{r}-\chi \phi_{r}^{2}=\frac{\rho V_{0}}{M_{c}}\left[\phi_{r}^{1 / 3}-1 / 2 \phi_{r}\right]
$$

where $\phi_{r}$ is the polymer volume fraction in the swollen network, $V_{0}$ is the molar volume of the solvent ( $106.2 \mathrm{~mL} / \mathrm{mol}$ for toluene), $\rho$ is the density of the rubber $(0.92 \mathrm{~g} / \mathrm{mL}$ for $\mathrm{NR})$, and $\chi$ is the Flory-Huggins polymer-solvent interaction term (0.393 for NR/toluene). The number of monomers between cross-links, $N_{c}$, was calculated from $V_{s}(\mathrm{~mol} / \mathrm{mL})$ obtained by swelling, where $N_{c}=\rho / M_{0} V_{s} ; M_{0}=68(\mathrm{~g} / \mathrm{mol})$ is the molecular weight of the isoprene monomer.

Dielectric spectroscopy measurements were performed using the Novocontrol Turnkey Concept N40 broadband spectrometer ${ }^{29}$ (Hundsangen, Germany). For dry experiments, vulcanized sample discs were mounted in the dielectric cell (ZGS Alpha Active Sample Cell) between two parallel gold-plated electrodes (BDS 1301 model). The thickness of the gold-plated electrodes was $2 \mathrm{~mm}$ and the diameters were $20 \mathrm{~mm}$ (upper) and $30 \mathrm{~mm}$ (down), respectively. The sample thickness was $1 \mathrm{~mm}$ and the diameter was about $15 \mathrm{~mm}$. The sample/electrode assembly was then mounted in the Novocontrol Quatro Cryosystem. For swollen experiments, vulcanized swelled specimens were fitted into a sealed liquid sample cell (BDS1308 model) to prevent the solvent evaporation. This electrode spacing can be varied to adjust the cell capacity. Preliminary swelling experiments 
were carried out first and the results were used to determine the optimum dimensions of the specimen inside the liquid cell. Subsequently, a dry sample with $0.5 \mathrm{~mm}$ thickness and ca. $5 \mathrm{~mm}$ diameter was used to prepare the swollen sample in the liquid cell. The final sample thickness in the swollen state was around $1 \mathrm{~mm}$. Possible gaps in the liquid cell were eliminated by lowering the electrode, which also avoided the flow of the sample. Two seal rings attached to the Teflon isolation were also employed to prevent the evaporation of solvent. The sample was maintained sealed until equilibrium swelling was reached. The equilibration time for swelling was between 24 and $48 \mathrm{hr}$, enabling the clear detection of different NR dipole movements. The liquid cell (introduced by the Cryosystem) was mounted in the dielectric cell using the similar procedure as in the dry measurements. Both dry and swollen dielectric experiments were carried out at $10^{3} \mathrm{~Hz}$ from $-160{ }^{\circ} \mathrm{C}$ to $100{ }^{\circ} \mathrm{C}$.

In situ stress-strain experiments coupled with synchrotron X-ray diffraction were carried out at the X27C beamline in the National Synchrotron Light Source (NSLS), Brookhaven National Laboratory (BNL). The wavelength was $0.1371 \mathrm{~nm}$. A coupled tensile machine (Instron) permits simultaneous mechanical and X-ray measurements. The dog-bone specimens were molded at 150 ${ }^{\circ} \mathrm{C}$ under 200 bar pressure. The thickness was $1 \mathrm{~mm}$ and the width of the narrower zone was 0.5 $\mathrm{cm}$. The deformation rate was $10 \mathrm{~mm} / \mathrm{min}$ and the experiments were carried out at room temperature. The maximum strain value was $400 \%$ due to the sample slip from the clamps. Two dimensional WAXD patterns were recorded using a MAR CCD camera. Exposure time for each image was $30 \mathrm{~s}$ and there was an interval of $5 \mathrm{~s}$ before the next exposure. The diffraction angle was calibrated by $\mathrm{Al}_{2} \mathrm{O}_{3}$ standard (provided by the National Institute of Standards and Technology). The images were processed using "POLAR" software (Stony Brook Technology and Applied Research, Inc.). The crystallinity index (C.I.) was calculated from the integration and 
correction of the equatorial $2 \mathrm{D}$ intensity WAXD profiles at the azimuthally range of $\pm 75^{\circ}$ using the "peak-fit" routine. All WAXD measurements were corrected for beam fluctuations, sample absorption and thickness variation during elongation. The calculation of the lateral crystal size was made following the protocol published elsewhere. ${ }^{30}$ The crystallite size was estimated by using the Scherrer equation $L_{h k l}=K \lambda /(\beta \cos \theta)$, where $L_{h k l}$ is the crystallite size in the direction perpendicular to the $(h k l)$ plane, $\lambda$ is the wavelength, and $\theta$ is the Bragg angle (half of the scattering angle). The value of $\mathrm{K}$ used herein was 0.89 .

In-situ X-rays and deformation experiment in the simultaneous mode ${ }^{31}$ offer the following advantages versus that in the sequential mode: (a) it makes possible to collect WAXD patterns in real time due to the high intensity synchrotron beam, (b) it permits to follow the exact dynamics of the process, thus avoiding erroneous conclusions regarding the evolution of microscopic mechanism, and (c) it allows to monitor the mechanical response simultaneously with the structural response, enabling the mapping of structural evolution during the stress-strain curve.

\section{Results and Discussion}

The X-ray powder diffraction patterns of various NR nanocomposites and corresponding neat clays are shown in Figure 1. As expected $\mathrm{Na}^{+}-\mathrm{MMT}$ does not show any changes in the d-spacing upon mixing with NR (Figure 1a). This suggests the formation of a conventional composite, where the polymer is not intercalated into the clay galleries. In contrast, both $\mathrm{d}-$-spacings of $\mathrm{O}-$ MMT (Figure 1b, left) and O-LAP (Figure 1c, left) increase after addition of NR. The d-spacing value in both O-MMT and O-LAP nanocomposites is about the same suggesting that a similar amount of polymer chains intercalate into the clay galleries. In the NR/O-LAP nanocomposite, the scattering peak was significantly broadened compared with that of the neat nanoclays, 
suggesting that the distribution of the particles becomes random. In contrast, sharper peaks are seen in the montmorillonite nanocomposite, suggesting good ordering is retained. Since the WAXD patterns of the nanocomposites shows no diffraction maxima at the original position as observed in the organoclays, it is apparent that almost all the layered silicates nanoparticles in the nanocomposites contain intercalated NR chains.

In our opinion the intercalation of the NR chains within clay layers should be critically addressed to the curatives like sulphur, accelerators and activators and also to the crosslinking process. Figure 2 shows the WAXD patterns for crosslink and uncrosslink NR/O-MMT nanocomposites in presence or not of the curatives. Uncrosslink NR containing only the O-MMT (15 phr) nanoclay particles (light gray line) exhibited a WAXD pattern showing a broad diffraction shoulder-peak which indicates that the silicate layers remain (roughly) parallel, or no longer evenly spaced, or that the distribution of the basal distances are not so regular. After addition of the curatives, some of the clay layers collapse decreasing the spacing between the groups of nanoclay stacks as it is evidenced in the WAXD pattern (gray line) by the presence of higher order $(00 l)$ reflections indicating a regular distribution of the NR chains in the organomodified interlayers. So, it is worth adding that the curatives did not penetrate the highly constrained interlayer region. Then, the portion of the NR chains staying within the interlayer region of the nanoclay is not participating in principle in crosslinking formation. Sharper and more well defined (001) reflection is evidenced after vulcanization process (showed also above in Figure $1 \mathrm{~b}$, right) of the nanocomposite (black line) in comparison with the uncrosslink nanocomposite (gray line). This suggests a large spatial ordering of the dispersed O-MMT nanoparticles after high temperature processing confirming that the crosslinking reaction takes place after the intercalation of the NR chains. 
The behavior of intercalated NR chains can also be supported by the DSC results (Figure 3). The calorimetric data indirectly revealed the effects of thermal history, interlayer organic surfactant on the intercalation processes. The quaternary alkyl ammonium salt exhibits an endothermic peak, corresponding to the melt transition ${ }^{32}$ at $67^{\circ} \mathrm{C}$ during the first heating (Figure 3a). The exothermic peaks at $23{ }^{\circ} \mathrm{C}$ and $54{ }^{\circ} \mathrm{C}$ observed during cooling (Figure 3b) correspond to the liquid-crystal phase transitions of different surfactant polymorphs. This behavior has been observed in alkyl compounds, such as triglycerides and other lipids with different crystalline forms. These compounds undergo different thermal transitions during crystallization processes. ${ }^{33}$ In the second heating step (Figure 3c), multiple endothermic peaks are seen, which confirms the heterogeneity of the ammonium salt having different surfactant crystalline structures during the thermal cycles. Regarding the compound of O-MMT, a well-defined endothermic transitions at $45^{\circ} \mathrm{C}$ and an exothermic transition at $37^{\circ} \mathrm{C}$ were observed during heating (Figures $3 \mathrm{a}$ and $3 \mathrm{c}$ ) and cooling (Figure 3b) steps, reflecting the melting and crystallization of local paraffinic packed regions, which is characteristic of 2:1 mica-type phyllosilicates modified with long alkyl chains. ${ }^{34}$ The presence of the broad and non-reversible endothermic transition at $100{ }^{\circ} \mathrm{C}$ during initial heating (Figure 3a) of O-MMT reflected the release of physically absorbed water. ${ }^{34 j}$ The presence of rubber chains inside the silicate gallery in $\mathrm{O}-\mathrm{MMT}$ is evidenced via the presence of multiple endothermic peaks in NR/O-MMT nanocomposite during initial heating (Figure 3a). These transitions can be attributed to the conformational changes of surfactant packed in the gallery and to variations of molecular environment due to polymer intercalation. To our knowledge, this is the first report that the use of DSC can trace the polymer intercalation through the thermal transitions of interlayer alkyl surfactant instead of following the intercalated polymer transitions. ${ }^{35}$ The pronounced shifts of the exothermic $\left(35^{\circ} \mathrm{C}\right.$ to $\left.21^{\circ} \mathrm{C}\right)$ and endothermic $\left(45^{\circ} \mathrm{C}\right.$ to 
$27^{\circ} \mathrm{C}$ ) peaks, corresponding to the crystallization (Fig. 3b) and melting (Fig. 3c) of organic surfactant in the gallery, respectively, in comparison with the unintercalated state, can be attributed to the disordering of the crystal structure of alkyl chains (e.g. loss of crystal symmetry) and the changes on interlayer packing density created by the penetration of NR chains. Finally, vulcanized NR materials exhibited a near constant secondary transition at $-58{ }^{\circ} \mathrm{C}$, which was due to the glass transition temperature of the polymer network.

The TEM images of various nanocomposite systems are shown in Figure 4. A highly inhomogeneous and aggregated microstructure is seen in the system of $\mathrm{NR} / \mathrm{Na}^{+}-\mathrm{MMT}$ (inset Figure 4a). Both XRD and TEM results suggest that $\mathrm{NR} / \mathrm{Na}^{+}-\mathrm{MMT}$ forms a conventional composite system. In contrast, the presence of finely dispersed and intercalated tactoids (nanoclay stacks) spaced 10 to $40 \mathrm{~nm}$ apart was seen in the systems of O-MMT (Figure 4b) and O-LAP (Figure 4c). However, it is interesting to note that there is some difference in the orientation of the clay particles: a highly oriented distribution of O-MMT nanoparticles is seen (Figure $4 \mathrm{~b}$ ) while a much more isotropic distribution is present for O-LAP (Figure 4c).

Small-angle X-ray scattering (SAXS) provides microstructure information about the distribution of clay particles in the NR matrix. In agreement with the TEM results, the SAXS analysis (A: face-on view; B and C: edge-on views) shows that the O-MMT clay particles are more preferentially aligned than O-LAP. Because of the platy character of the O-MMT clay particles, the edge-on view of the O-MMT based nanocomposites exhibited a highly anisotropic pattern (Top patterns in Figures 5B and 5C) due to the particle orientation parallel to the plane of the sample. In contrast, the face-on view leads to an isotropic pattern (Top Fig. 5A) due to the random distribution of the particles with respect to the in-plane direction. In addition, the nanocomposites based on NR with unmodified clay (data not shown) or O-LAP (Figure 5, 
bottom diagram) also showed an isotropic distribution of the clay particles. The difference between $\mathrm{O}-\mathrm{MMT}$ and $\mathrm{O}-\mathrm{LAP}$ can be attributed to the differences in the aspect ratio (the ratio between the lateral dimension and the thickness) of the particle. The larger aspect ratio of MMT particles leads to higher orientation than LAP clays with the smaller aspect ratio.

The effect of dispersion of organically modified layered silicate particles on the viscoelastic properties of the vulcanized NR matrix was studied by DMA, where the dynamic properties of neat NR and NR composites were examined over a wide temperature range $\left(-130\right.$ to $\left.50{ }^{\circ} \mathrm{C}\right)$. The storage modulus and $\tan \delta$ as a function of temperature are shown in Figure 6. It was found that the addition of $\mathrm{Na}^{+}-\mathrm{MMT}$ did not change the properties of NR. However, an increase in the modulus and a shift in the $\mathrm{T}_{\mathrm{g}}$ to higher temperatures compared to pure NR were seen in the $\mathrm{O}-$ MMT based nanocomposite. Since the results from calorimetric analysis (Figure 3) and swelling measurements (Table 2) indicate that the organoclay does not affect the extent of curing, the increase in modulus can be attributed to (a) the hydrodynamic effect of the clay and (b) the formation of physical crosslinks due to the presence of clay. On the other hand, the shift in $\mathrm{T}_{\mathrm{g}}$ implies a strong interaction between the filler and the matrix, which results in a reduction of the mobility of the polymer chains in the presence of the clay.

Effects of nanoclay on the microstructural network, topological constrain and non-elastically active components of NR have been studied by dielectric spectroscopy. The existence of the dielectric moment on cis-poly(isoprene) with two components ${ }^{36}$ allows us to monitor two kinds of relaxation modes: one related to the local segmental motion (the segmental mode) and another (slower motion) related to the breathing of the whole chain (the normal mode). Consequently, cis-poly(isoprene) can be viewed as a model system to study the dynamics of relaxation modes of entangled ${ }^{37}$ or dilute ${ }^{38} \mathrm{NR}$, and dry crosslinked rubber networks. ${ }^{39}$ Figure 7 shows the dielectric 
loss $\left(\varepsilon^{\prime \prime}\right)$ over a wide range of temperatures at the fixed frequency of $10^{3} \mathrm{~Hz}$. The dash and solid lines represent the dry and swollen systems, respectively for (a) unfilled NR, (b) NR/Na ${ }^{+}-\mathrm{MMT}$ and (c) NR/O-MMT nanocomposites.

Dry vulcanized NR shows a main peak at $-34{ }^{\circ} \mathrm{C}$, which can be assigned to the segmental relaxation, $\left(\alpha_{\mathrm{dry}}\right)$, and the secondary relaxations at low temperatures (below $T_{g}$ ) can be assigned to the localized motion in the glassy state. No significant change on the molecular dynamics by the addition of nanoparticles in the bulk state has been observed. The presence of the extra relaxation mode at $-80{ }^{\circ} \mathrm{C}$ in $\mathrm{NR} / \mathrm{Na}^{+}-\mathrm{MMT}$ nanocomposite (Figure $7 \mathrm{~b}$ ) is most likely due to the electric dipole rotations of the absorbed water in the silicate gallery. ${ }^{40}$ However, in the swollen samples, the physical constrains present in the dry samples are no longer effective because of the slippage of the entanglements. ${ }^{41}$ Thus, the swelling process induces the occurrence of a low frequency transition, and a broad normal mode, $N$, due to the much faster chain dynamics. In addition, three narrow distributions of segmental relaxation times, corresponding to the motions of transversal dipoles: $\alpha_{\mathrm{I}}\left(-100^{\circ} \mathrm{C}\right), \alpha_{\mathrm{II}}\left(-130^{\circ} \mathrm{C}\right), \alpha_{\mathrm{III}}\left(-145^{\circ} \mathrm{C}\right)$, were also observed in both neat NR (Figure $\left.7 \mathrm{a}\right)$ and $\mathrm{NR} / \mathrm{Na}^{+}-\mathrm{MMT}$ composite (Figure $7 \mathrm{~b}$ ). However, the NR/O-MMT swollen nanocomposite (Figure 7c) shows only one main dipole distribution, which is related to the segmental motion at $100{ }^{\circ} \mathrm{C}\left(\alpha_{\mathrm{I}}\right)$. It is conceivable that micro-scale segmental variations due to the distribution of different network components (topological constrains and defects) yield a more homogeneous distribution of transversal dipole domains for the NR/O-MMT nanocomposite. Since all the samples exhibit similar molecular characteristics (i.e. molecular weight $\left(M_{w}\right)$ and polydispersity $\left.\left(M_{w} / M_{n}\right)\right)$ before and after processing (see Table 2), the variations on the network microstructure cannot be solely attributed to these molecular variables. Such a difference can best be explained by the presence of a higher amount of dangling end chains, loops, long tail chains and 
uncrosslinked chains in neat $\mathrm{NR}$ and $\mathrm{NR} / \mathrm{Na}^{+}-\mathrm{MMT}$ samples compared to that in NR/O-MMT. The presence of the long tail components with high mobility has also been observed by NMR studies of swollen crosslinked NR samples. ${ }^{42}$ It has been proposed that these components contribute to a larger amount of network defects in the NR matrix and manifest themselves in the presence of an extra and highly mobile region in the loss curve.

The addition of nanoclay in NR appears to provide a relatively more regular polymer network microstructure (although consisting of several different components) as a consequence of the presence of many and short network points (physical and chemical) homogeneously distributed as well as the high number of interactions between the NR chains and the nanoclay which are in turns ultimately determinated from the high surface area and anisotropy (low aspect ratio) of the nanoclay sheets in comparison to the unfilled NR matrix or conventional NR composites with poor particle distribution as in those based on unmodified NR/Na ${ }^{+}-\mathrm{MMT}$. The normal mode of the NR/O-MMT nanocomposite overlaps with the dipole distribution due to the NR chains adsorbed on the outer surface of the nanoclay particles (I.A.: interfacially adsorbed polymer). Further studies of physically adsorbed polymer on the modified nanoclay surface of NR nanocomposites by dielectric spectroscopy are underway and will be published elsewhere.

Figure 8 shows the stress-strain behavior (during stretching and recovery) for unfilled NR (solid line), $\mathrm{NR} / \mathrm{Na}^{+}-\mathrm{MMT}$ (dash line), NR/O-MMT (dot dot line) and NR/O-LAP (dot line) nanocomposites. WAXD patterns at different strain ratio $(\alpha)$ are also inserted for the unfilled NR (A), NR/ $\mathrm{Na}^{+}-\mathrm{MMT}$ (B) and NR/O-MMT (C) samples as a useful guide to follow the variation of crystallization under stretching. Images corresponding to NR/O-MMT nanocomposites exhibit preferred orientations of (100), (200) and (300) reflections from the nanoclays upon stretching. It is seen that oriented nanoclay reflection peaks (C images) begin to appear at a relatively low 
strain $(\alpha<1)$. The intensities of these reflections increase with strain during stretching until a maximum alignment is reached (at $\alpha=4$ ). The stress-strain curves show a hysteresis, which was also found in pure vulcanized NR..$^{30,43}$ This hysteresis corresponds with the different appearance in the WAXD images collected simultaneously during the tensile test. It has been reported that a dramatic deviation from the behavior of rubber elasticity can take place with the increase of strain $^{44}$, which is seen in the NR/O-MMT nanocomposite. It is interesting to note that the hysteresis cycle is higher for the NR/O-MMT sample than the rest of the samples. In addition, crystal reflections (in WAXD images) of unfilled NR appear at a higher strain than those for the $\mathrm{NR} / \mathrm{Na}^{+}-\mathrm{MMT}$ and NR/O-MMT samples. No evidence of orientation in the amorphous phase has been made based on the WAXD analysis. If there was any oriented amorphous phase, the total fraction must be small. This finding is in contrast with the study by Rault et al..$^{24 c, 24 d}$ who have reported orientation of the amorphous phase using H NMR. The degree of crystallization is clearly evidenced from the normalized and corrected linear diffraction profiles as shown in Figure 9.

Figure 10 shows the evolution of crystallinity index (CI) with strain for the chosen samples, which all show a significant hysteresis cycle as in the stress-strain curves in Figure 8. Contrary to the stress values during the stretching-recovery cycle, the CI values are larger during the recovery processes than those during the stretching. This behavior can be explained by the formation of different types of strain-induced crystallites, which has been reported earlier. For example, Andrews et al..$^{45}$ suggested a variety of induced-crystallization stages in NR at different strains: spherulitic forms (0-50\%), row-nucleated shish-kebabs (100-200\%) and extended chain crystals $(>400 \%)$. 
The onset strain for crystallization $\left(\alpha^{0}\right)$ was determined by the interception of the regression line (dot line) in the plot of CI against $\alpha$ (Figure 10). In the unfilled NR sample (Figure 10a), the highest $\alpha^{0}$ value observed is in concordance that reported in the previous studies. ${ }^{31,43}$ The lowest $\alpha^{0}$ value for NR/Na+ ${ }^{+}$MMT (Figure 10b) and NR/O-MMT (Figure 10c) samples were found to be 1.4 and 1.2, respectively. For NR/O-LAP sample (Figure 10d), the $\alpha^{0}$ value was 2.3, which is also in good agreement with the reported values for NR filled with carbon black, ${ }^{24 a, 24 c, 24 d}$ calcium carbonate $^{24 \mathrm{~b}}$ and silica. ${ }^{24 \mathrm{e}}$ Regarding the overall $\mathrm{CI}$ in NR/O-MMT and NR/O-LAP, the values were significantly higher than those in the rest samples. For unfilled NR (Figure 10a), the CI was $25 \%$ at a strain $\alpha=5$. The highest $\mathrm{CI}$ value during the stretching process was found in NR/OMMT nanocomposite; $\mathrm{CI}=48 \%$ at a strain $\alpha=4$ (Figure $9 \mathrm{c}$ ). For NR/Na ${ }^{+}-\mathrm{MMT}$ and NR/OLAP samples at $\alpha=4$, the CI was $14 \%$ and $28 \%$ respectively. It is evidenced that the aspect ratio of the layered silicate particles plays a key role on the apparition of the first crystallites as well as on the final crystalline content during the deformation of the materials.

This effect was also reflected on the strain-induced crystallization mechanism of the chosen nanocomposite samples. While for the unfilled NR (Figure 10a) and the NR/O-LAP (Figure 10d), a single crystallization step during the stretched and recovery stages was detected, a welldefined dual crystallization mechanism was evidenced for NR/O-MMT (Figure 10c) and $\mathrm{NR} / \mathrm{Na}^{+}-\mathrm{MMT}$ nanocomposite (Figure 10b) samples. As it can be observed in Figure 4a, $\mathrm{NR} / \mathrm{Na}^{+}-\mathrm{MMT}$ composite contains single nanoclay platelets (in addition to tactoids) from the delamination process of the micron size silicate particles. This might be the reason for the change in the crystallization rate and the corresponding nearly equal crystallization onset values. Therefore, the first step at $\alpha<3$ is probably related to the orientation and alignment of highly anisotropic nanoclay particles, while in the second step $(3 \leq \alpha \leq 4)$, these highly anisotropic 
nanoparticles are completely aligned along the direction of the deformation forming a physical network which favors the alignment of the NR chain and thus the crystallization rate increase. This behavior was absent in the NR/O-LAP nanocomposite (Figure 10d), where a single crystallization step exhibiting a slope value similar to that of unfilled NR was found as a consequence of the much less anisotropy exhibited by the O-LAP nanoparticles in the NR matrix in comparison with the $\mathrm{O}-\mathrm{MMT}$. Although the crystallization rate in NR/O-MMT is about two times more than the rest samples, there was no clear relationship between the slope values and the final crystalline content. This implies that some other effects such as crystal morphology may also play a role.

To clarify this hypothesis, the variation of lateral dimension in the crystal during deformation was analyzed. Figure 11 shows the variations of the crystallite size estimated from the 200 and 120 reflections. Interestingly, $\mathrm{L}_{200}$ (Figure 11a) and $\mathrm{L}_{120}$ (Figure 11b) showed an opposite trend (i.e., the lateral dimension along 200 direction increased and decreased along the 120 direction) for all the samples except for NR/O-MMT, where the lateral size dimensions calculated along these two directions were almost unchanged. From these results, we suggest that the morphology of the crystallites formed in the NR/O-MMT nanocomposites under elongation is somewhat different from those formed in the rest of the samples.

\section{Conclusions}

The influence of nanoclay on the morphological and microstructural changes of NR network has been analyzed by dielectric spectroscopy and synchrotron wide-angle X-ray diffraction. It is clear that the polymer intercalation can be evidenced through the thermal transitions of the interlayer alkyl surfactant from DSC traces. The inclusion of highly anisotropic nanoparticles 
leads to microscale segmental variations, in fact, giving rise to the formation of a relatively homogeneous network structures in rubber. The presence of extra dipole distribution corresponding to more mobile components which are responsible of the network imperfections can be significantly reduced by addition of the organoclay. Moreover, the presence of strong interfacial adhesions between nanoparticles-rubber matrix can induce an early promotion and enhancement of overall crystallization of NR chains under uniaxial stretching. Furthermore, high anisotropic nanoclay particles induce a crystalline morphology different from those by silicates with lower aspect ratio. The interplay between all of these parameters could explain why the reinforcing effects in NR/clay nanocomposites are manifested at low filler loadings.

\section{Acknowledgements}

The authors gratefully acknowledge the financial support of the Spanish Ministry of Education (MEC) through project MAT 2004-00825. This work made use of the Cornell Center for Materials Research Experimental Facilities. Additionally, J. Carretero-González acknowledges support from MEC in the form of a FPI grant, R. Verdejo a Juan de la Cierva contract from MEC and B. S. Hsiao is supported by the National Science Foundation (DMR-0405432). 
Figure 1. Left: XRD patterns of (a) $\mathrm{Na}^{+}-\mathrm{MMT}$, (b) O-MMT, and (c) O-LAP nanoclays. Right: XRD patterns of (a) NR/Na ${ }^{+}-\mathrm{MMT}$, (b) NR/O-MMT, and (c) NR/O-LAP compounds.
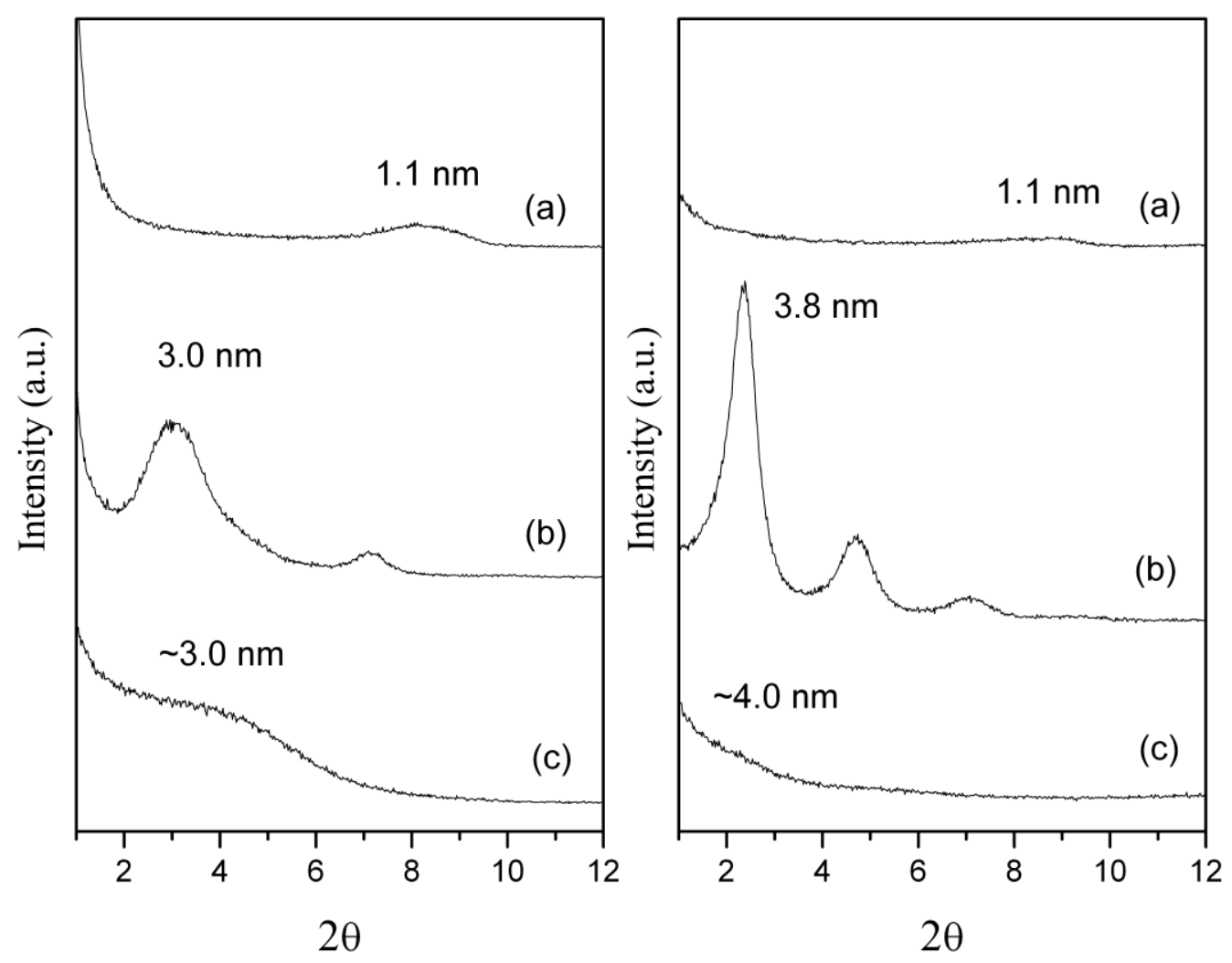
Figure 2. XRD patterns corresponding to the cross-linked NR/O-MMT nanocomposites (dark line), un-cross-linked NR/O-MMT (medium line), and un-cross-linked* NR/O-MMT without curatives (light line).

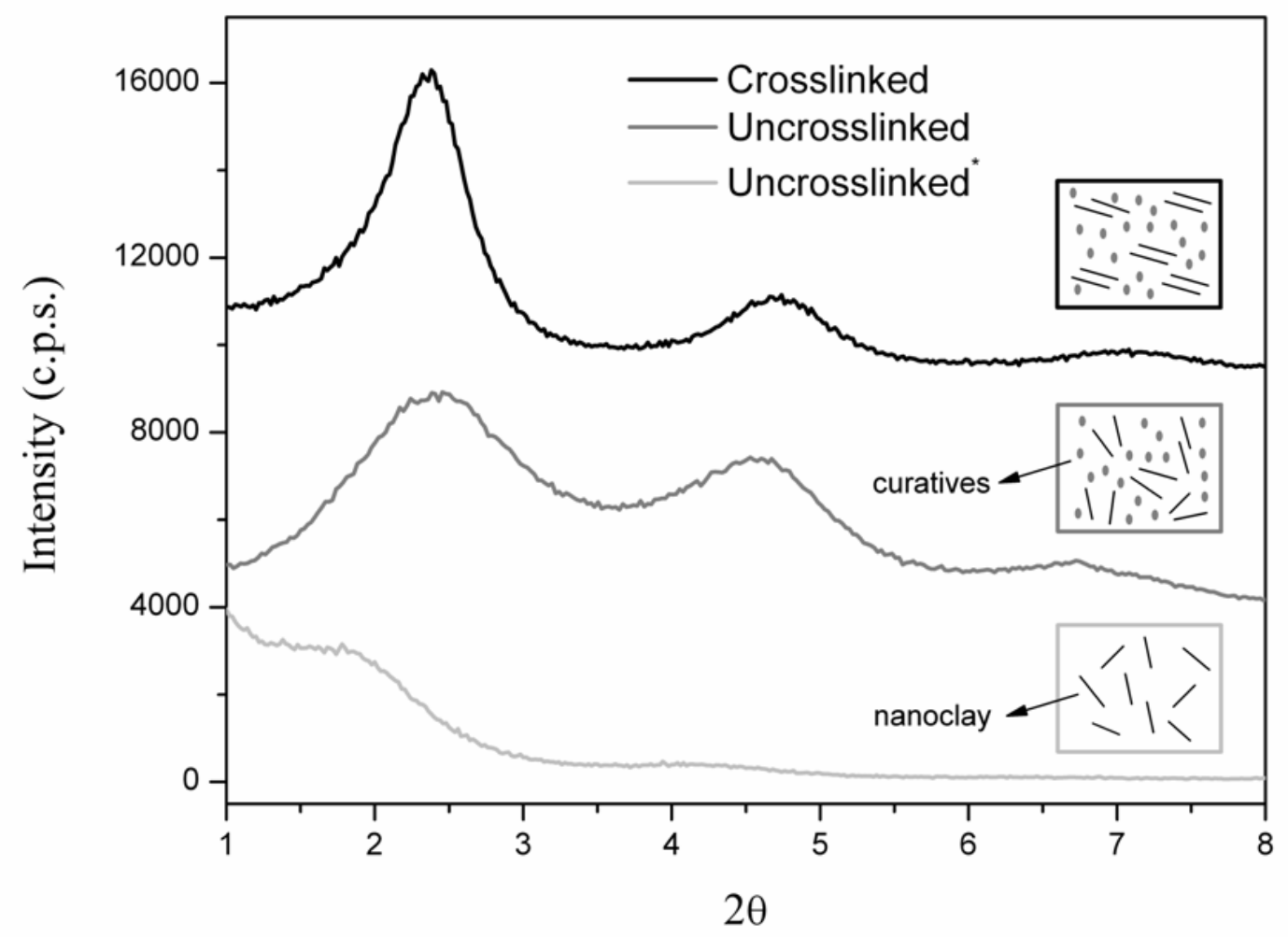


Figure 3. DSC data for (a) heat, (b) cool, (c) second heat cycles corresponding to the surfactant (一), O-MMT (-), NR/O-MMT (-) and unfilled NR (-) samples.
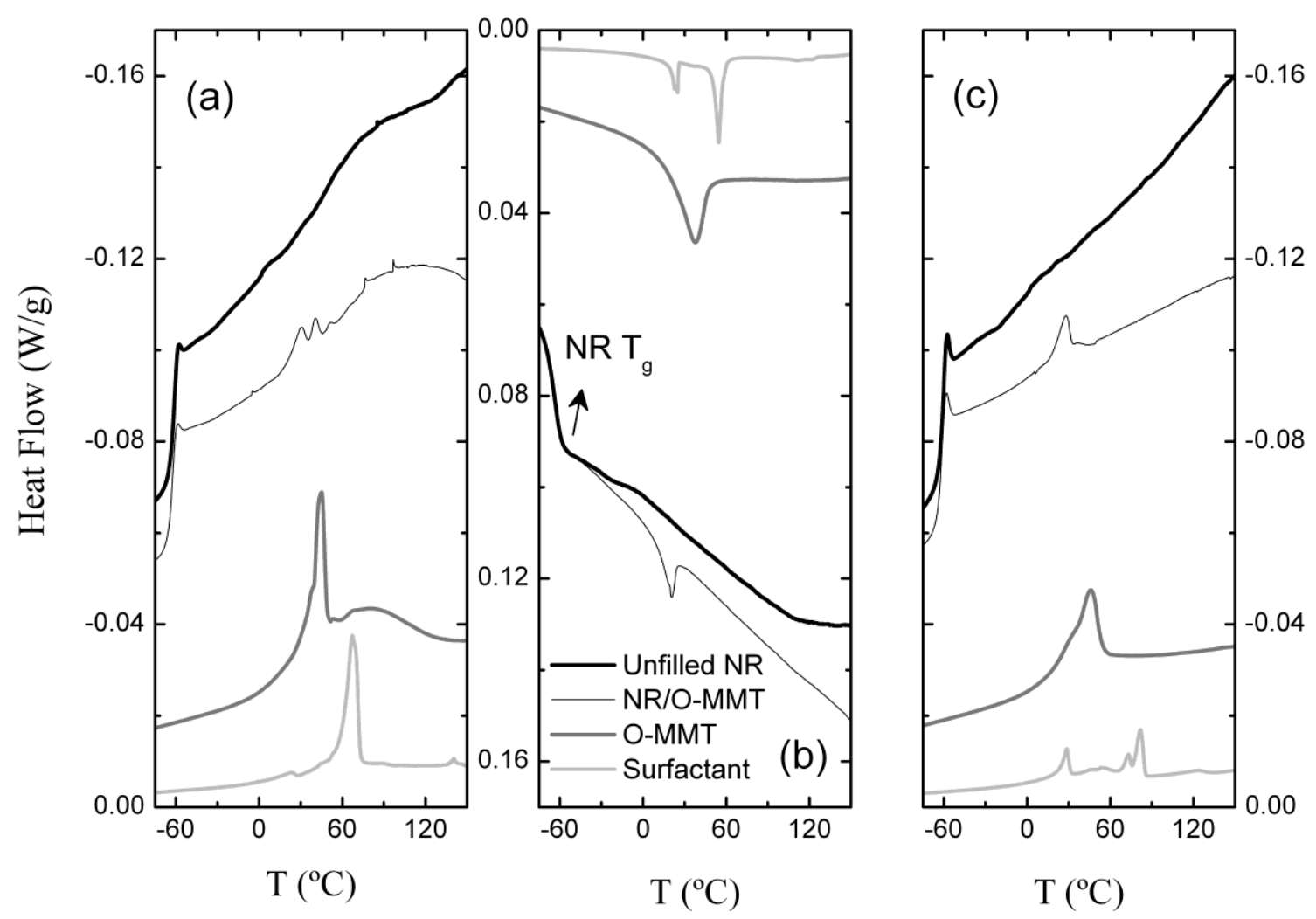
Figure 4. High magnification TEM images for (a) NR/Na ${ }^{+}-\mathrm{MMT}$, (b) NR/O-MMT, and (c) NR/O-LAP compounds. The inset images represent the dispersion level of nanoclays at low magnification range $(20 \mathrm{Kx}-50 \mathrm{Kx})$.
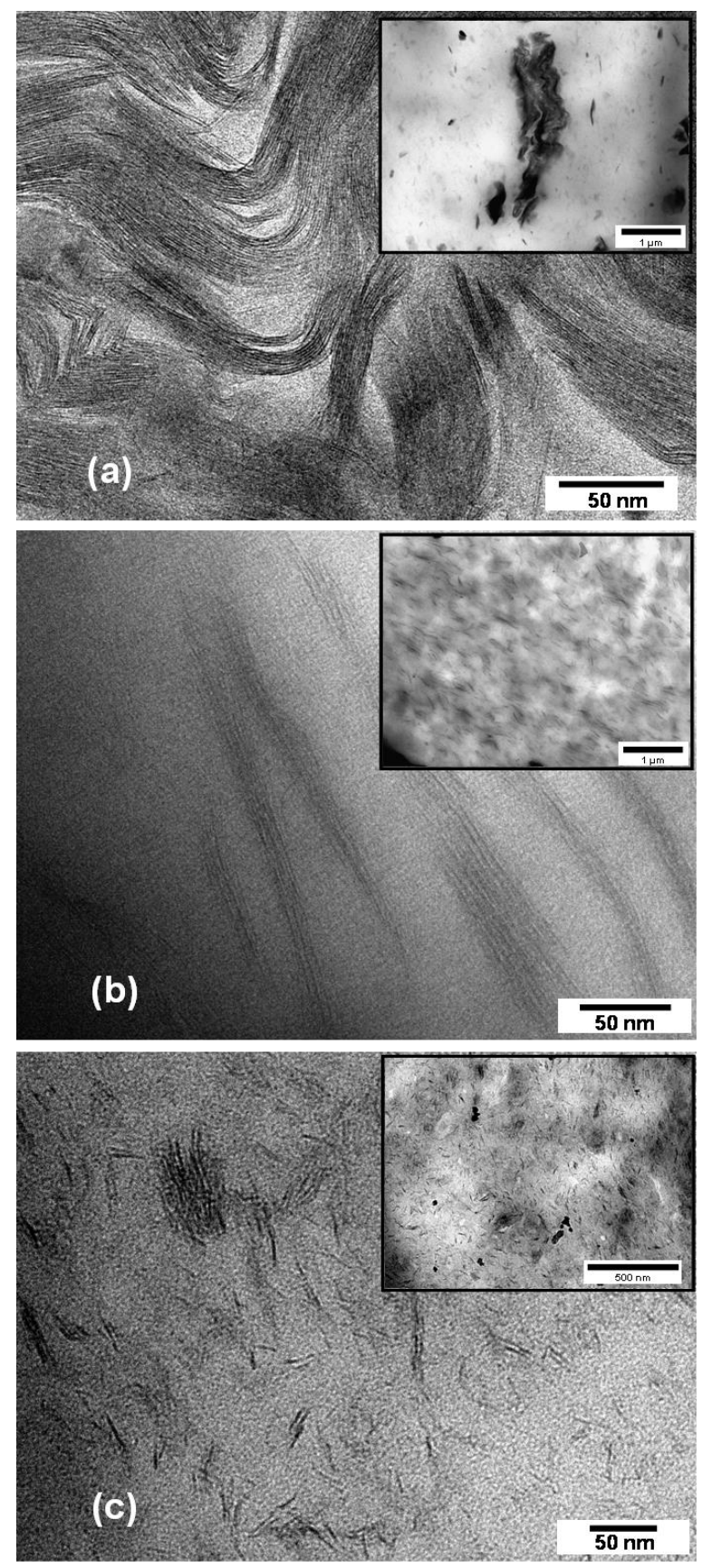
Figure 5. 2D SAXS patterns (A: face-on view; B and C: edge-on views) for the unstretched state of the nanocomposites loaded with 15 phr of nanoclay: (up) NR/O-MMT and (down) NR/OLAP samples.

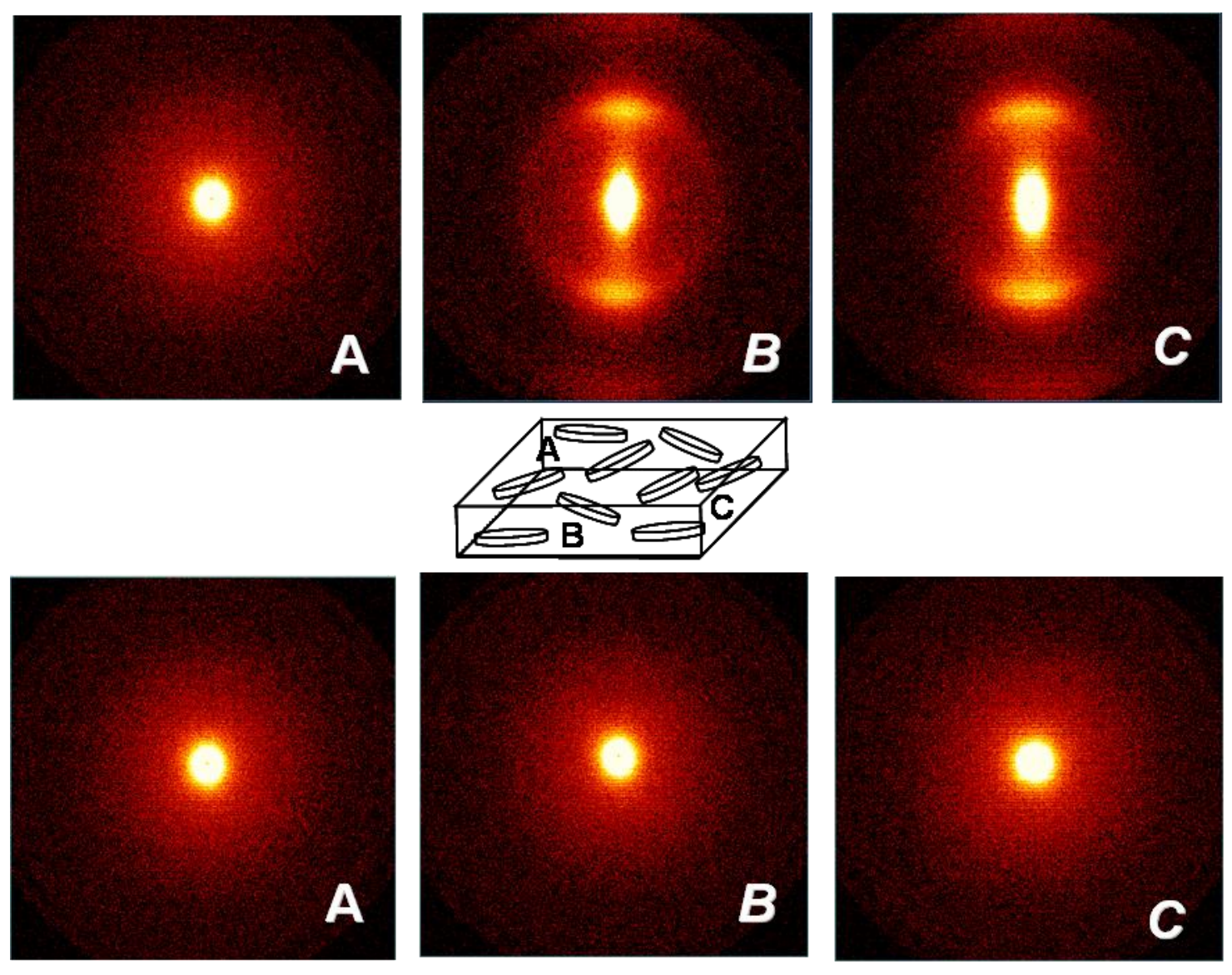


Figure 6. Temperature dependence of elastic modulus E' (left axis) and tan $\delta$ (right axis) for vulcanized unfilled NR (solid line), NR/Na ${ }^{+}-\mathrm{MMT}$ (dash line) and NR/O-MMT (dot line) compounds.

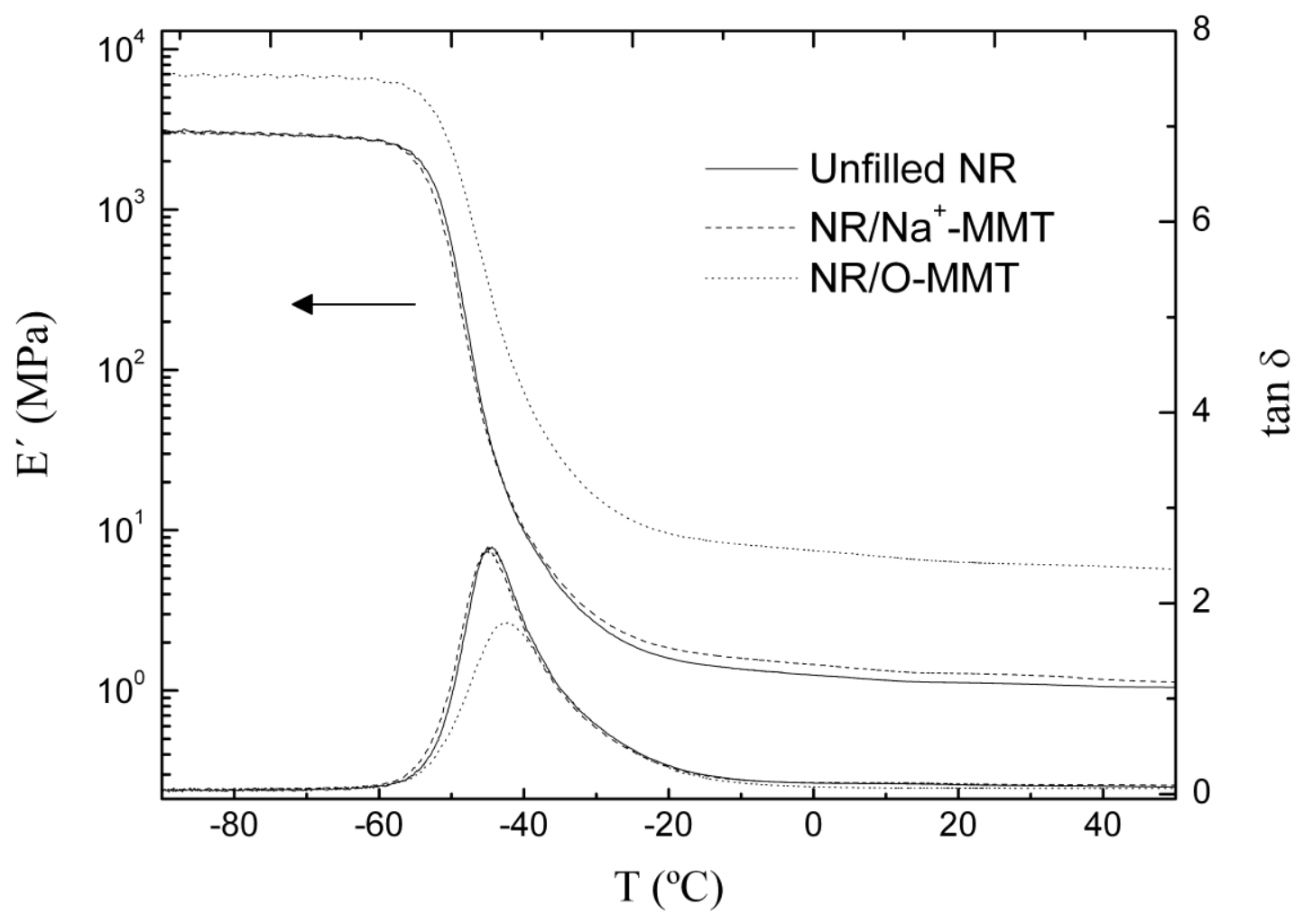


Figure 7. Temperature dependence of $\varepsilon^{\prime \prime}$ at $10^{3} \mathrm{~Hz}$ for dry (dash line) and swollen (solid line) cross-linked NR networks, corresponding to (a) unfilled NR, (b) NR/Na ${ }^{+}-\mathrm{MMT}$ and (c) NR/OMMT samples. Ideal microstructure including the network points distribution and the layered clay dispersion on the NR matrix are schematically represented in the inset of each graph.

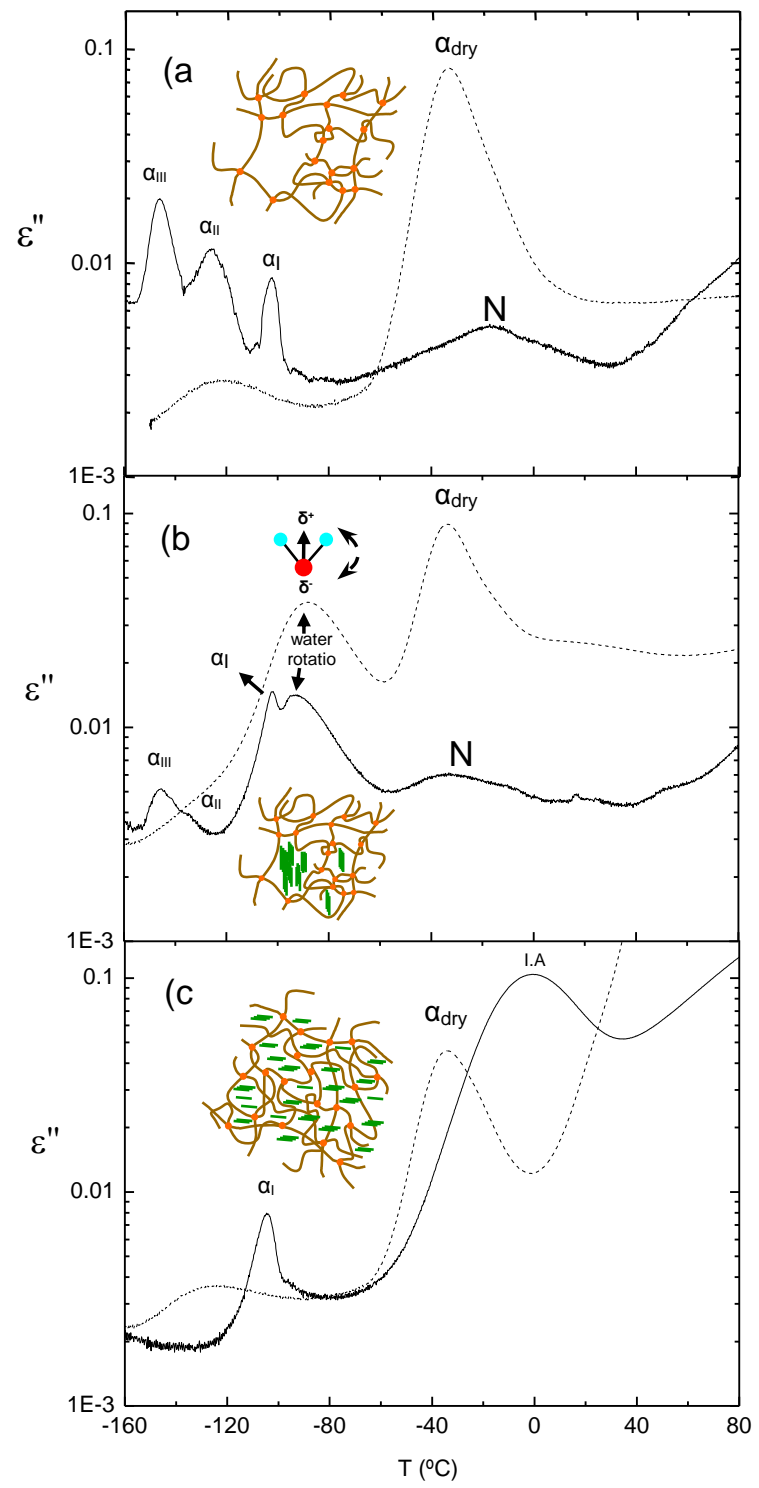


Figure 8. Stress-strain curves and selected synchrotron WAXD patterns during extension and retraction cycles for the chosen samples. The corresponding stress-strain curve for the NR/O-LAP nanocomposites is included for comparison. 2D WAXD patterns for (A) the unfilled NR, (B) $\mathrm{NR} / \mathrm{Na}^{+}-\mathrm{MMT}$ and (C) NR/O-MMT are illustrated at selected strains.
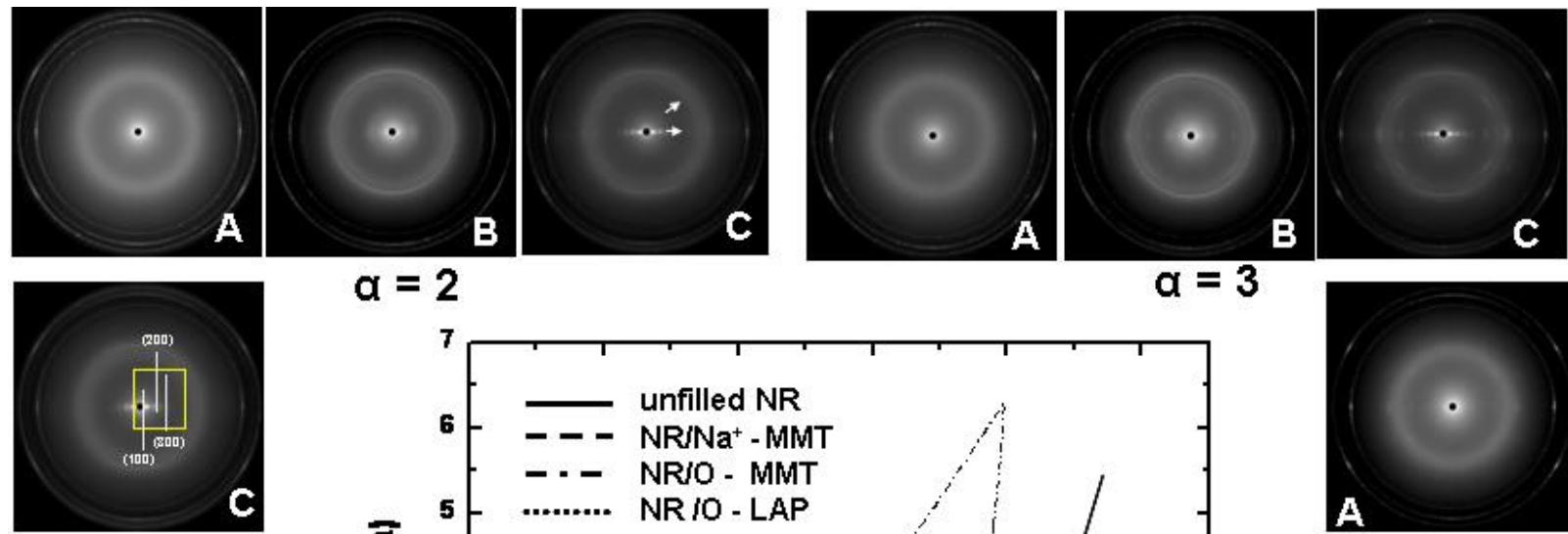

$$
a=2
$$

$\alpha=3$
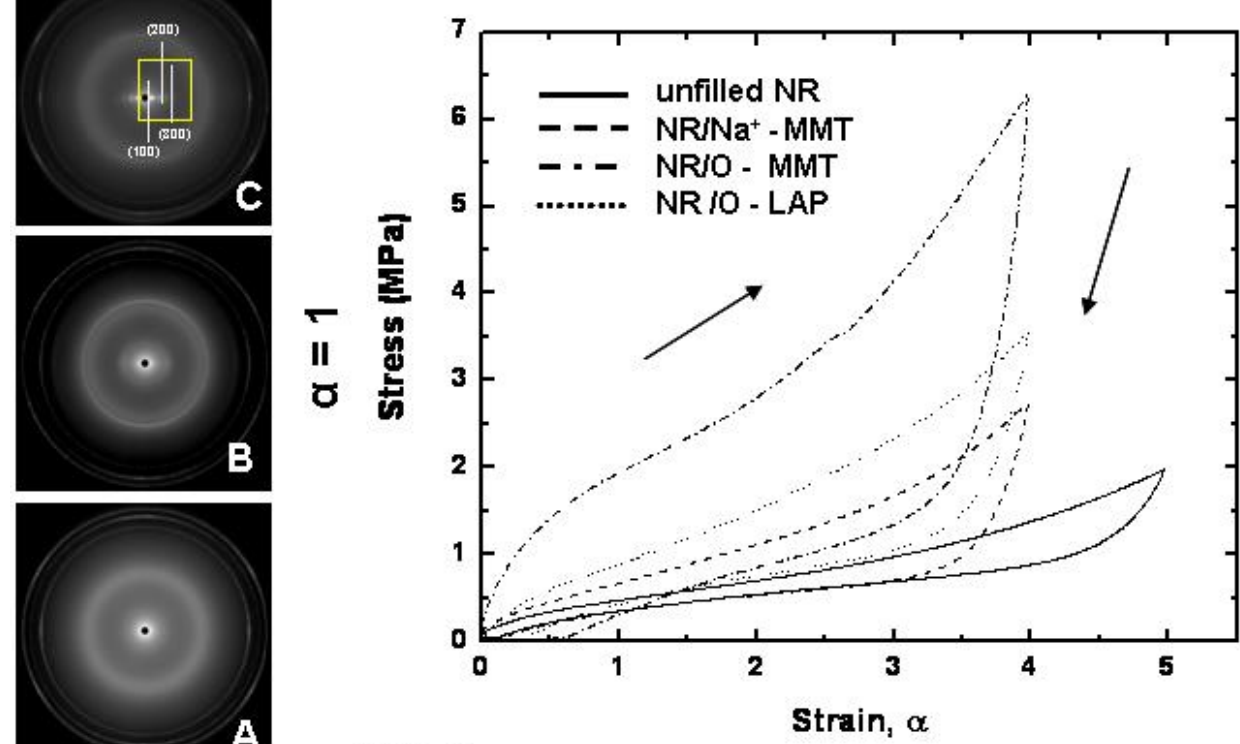

A

$$
a=2
$$
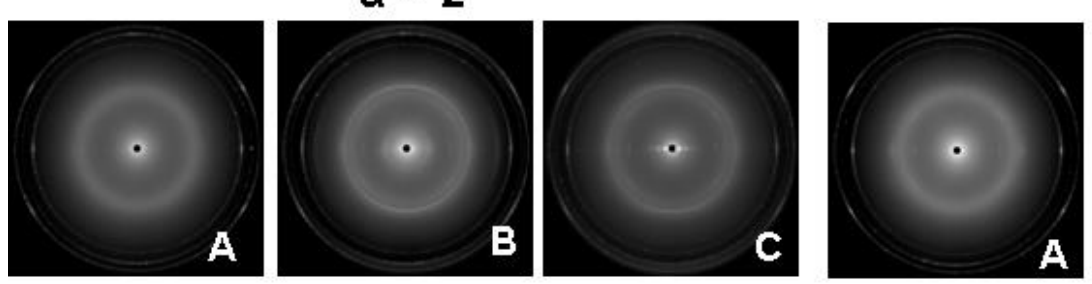

$a=3$
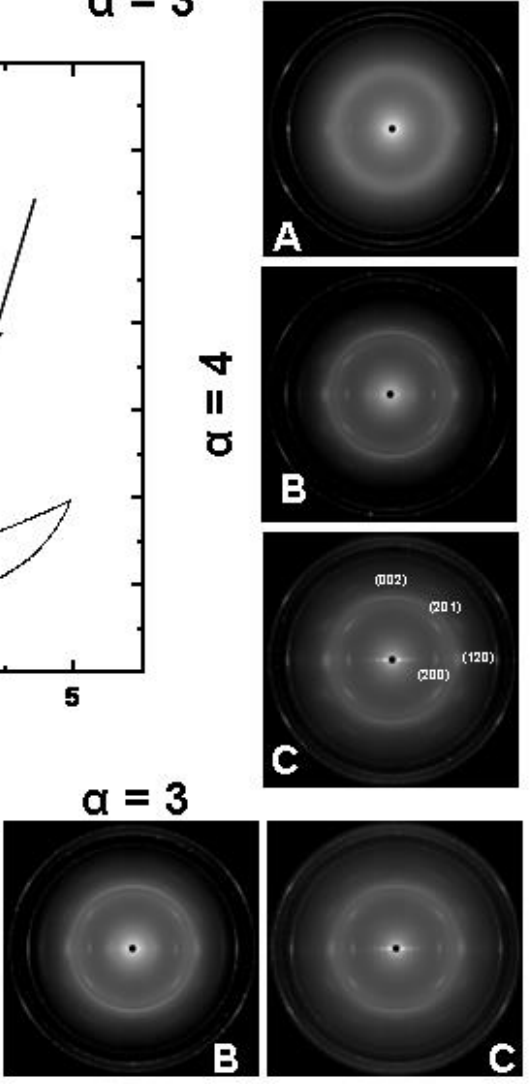
Figure 9. Normalized and corrected linear diffraction profiles for (a) unfilled NR, (b) NR/Na+-MMT and (c) NR/O-MMT samples. The strain-induced crystallization (SIC) was evidenced by (200) and (120) reflections from the NR. The samples containing the silicate showed an extra diffraction peak at high s values corresponding to the layered silicate. This peak did not affect to the crystallinity index calculation.
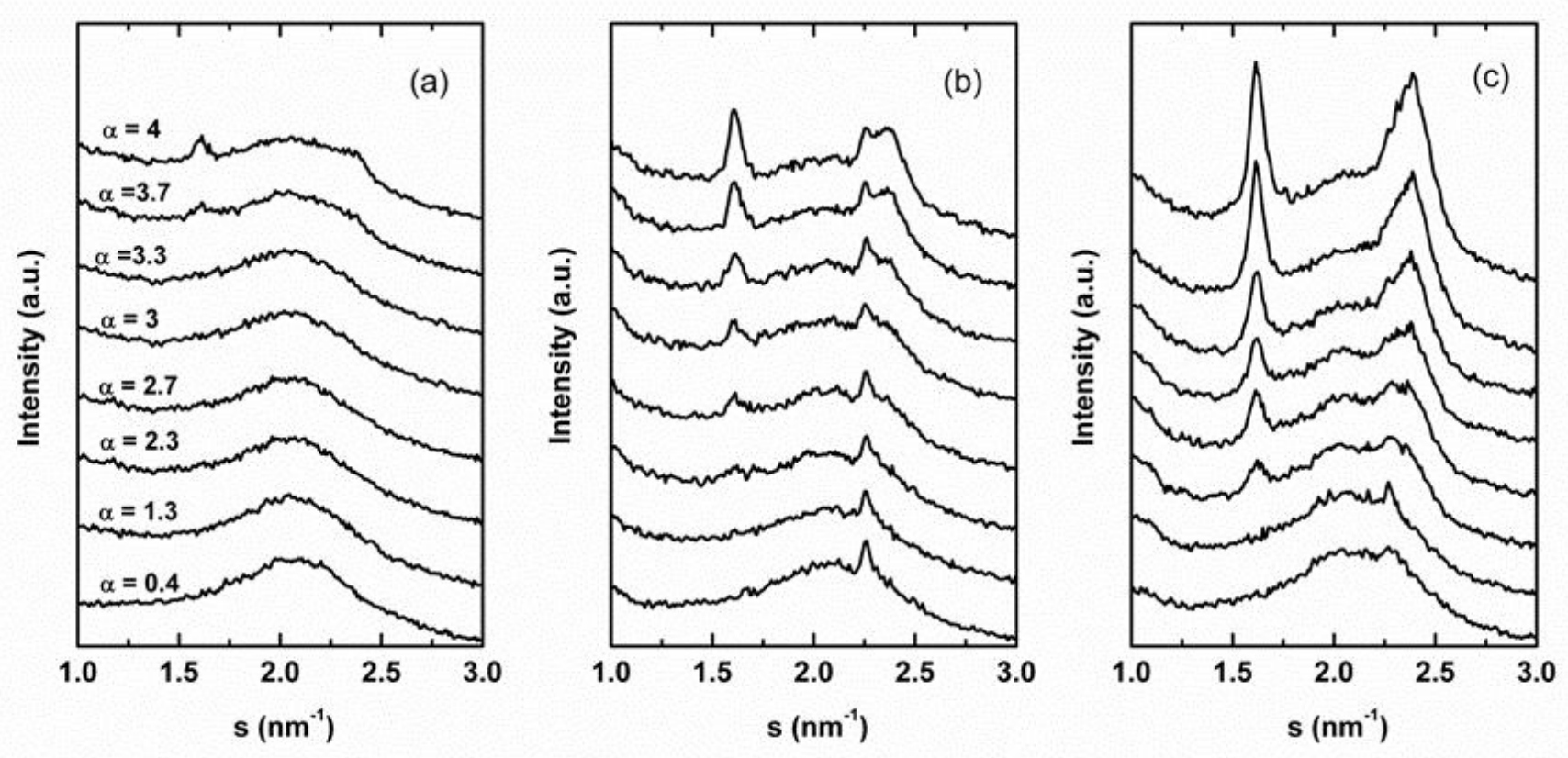
Figure 10. Crystallinity index (C.I.) as a function of strain during the stretch-recovery cycle for: (a) unfilled NR, (b) NR/Na ${ }^{+}-\mathrm{MMT}$, (c) NR/O-MMT, and (d) NR/O-LAP samples. Solid line is only a guide to the eye.

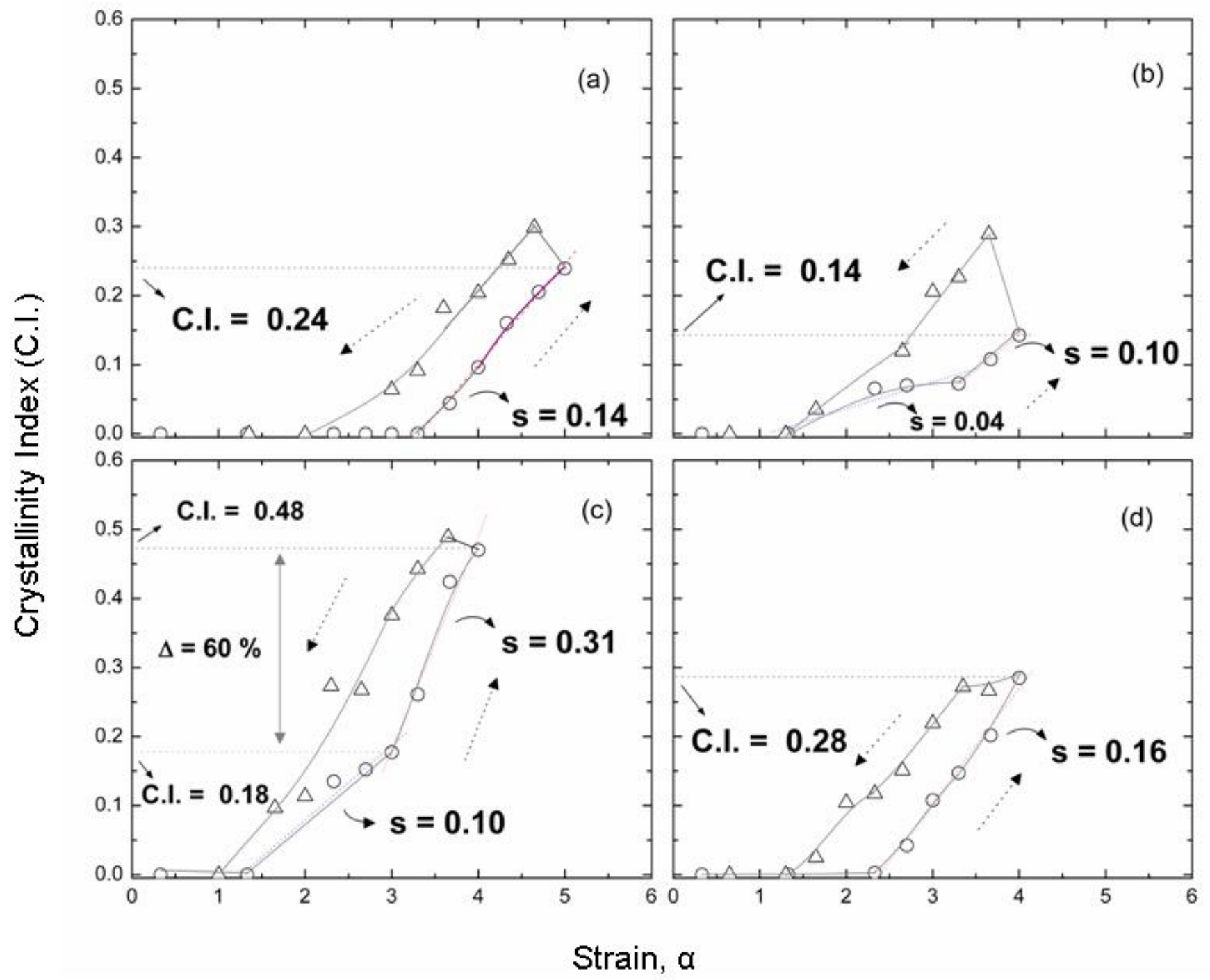


Figure 11. Variations of the lateral crystallite size with strain determined from (a) the $200\left(L_{200}\right)$ and (b) $120\left(L_{120}\right)$ reflections during the stretching process (arrows indicate the stretching process).

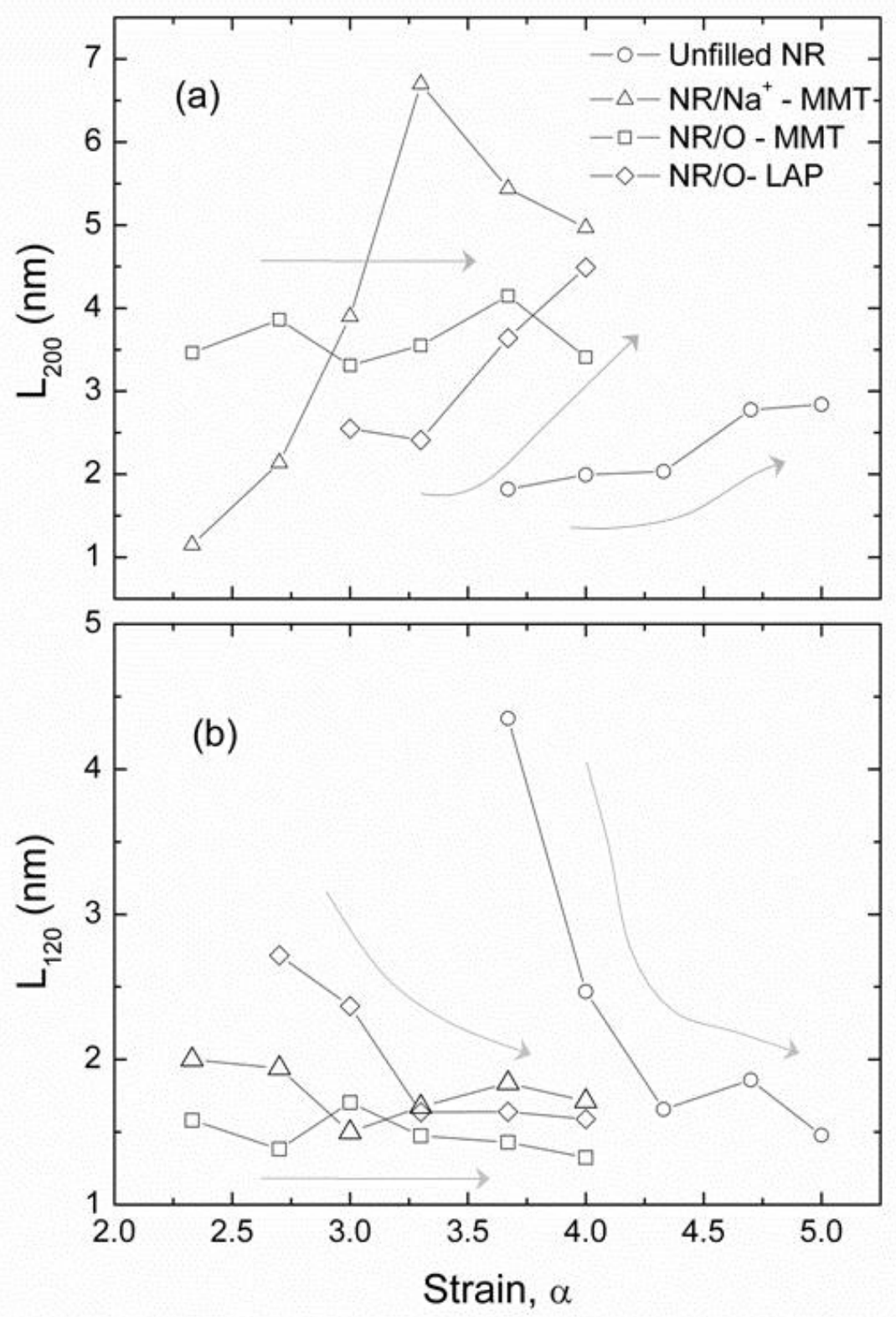


Table 1. Principal features of the layered silicates employed in this work. The layered silicates were ionically exchanged with dimethyl dehydrogenated tallow quaternary ammonium ion. The ditallow was a mixture of dimethylammonium surfactants with various carbon chain lengths of ca. $65 \%$ of $\mathrm{C}_{18}, 30 \%$ of $\mathrm{C}_{16}$ and $5 \%$ of $\mathrm{C}_{14}$.

\begin{tabular}{ccccc}
\hline Clay & $\begin{array}{c}\text { Platelet size } \\
(\mathrm{nm})\end{array}$ & $\begin{array}{c}\mathrm{CEC}^{*} \\
(\mathrm{meq} / \mathrm{g})\end{array}$ & $\begin{array}{c}\text { d-Spacing } \\
(\mathrm{nm})\end{array}$ & $\begin{array}{c}\text { Surfactant } \\
(\% \mathrm{wt})\end{array}$ \\
\hline $\mathrm{Na}^{+}-$MMT & $\sim 100-500$ & 0.92 & 1.1 & 0 \\
O-MMT & $\sim 100-500$ & 0.97 & 3.0 & 40.2 \\
O-LAP & $\sim 25-50$ & 0.74 & $\sim 3.0$ & 32.8 \\
\hline
\end{tabular}

${ }^{*}$ Cation Exchange Capacity (C.E.C.) was determined by thermogravymetric analysis after Soxhlet filtration process of the organo-modified layered silicate particles. CEC for the $\mathrm{Na}^{+}-\mathrm{MMT}$ was obtained from Material Safety Data Sheets provided by Southern Clay Products. 
Table 2. Weight-average molecular weight, $M_{w}(\mathrm{~g} / \mathrm{mol})$, and polydispersity indices, $M_{w} / M_{n}$, for pristine unmasticated-NR* and for NR extracted from uncrosslinked NR-nanoclay materials after masticationmixing procedure were determined by gel permeation chromatography (GPC) analysis with THF as eluant. Crosslinking density, $V_{S}(\mathrm{~mol} / \mathrm{mL})$, average mass of network chains, $M_{c}(\mathrm{~g} / \mathrm{mol})$, and number of monomers between crosslinks, $N_{c}$, for the crosslinked materials obtained from swelling experiments (48 h) using toluene at $30^{\circ} \mathrm{C}$ is also summarized.

\begin{tabular}{cccccc}
\hline Material & $\begin{array}{c}M_{w} \times 10^{-4} \\
(\mathrm{~g} / \mathrm{mol})\end{array}$ & $M_{w} / M_{n}$ & $\begin{array}{c}V_{s} \times 10^{-4} \\
(\mathrm{~mol} / \mathrm{mL})\end{array}$ & $\begin{array}{c}M_{c} \times 10^{-4} \\
(\mathrm{~g} / \mathrm{mol})\end{array}$ & $N_{c}$ \\
\hline Unmasticated-NR & 70.8 & 5.7 & - & $2.0^{*}$ & - \\
Unfilled NR & 24.2 & 2.5 & 0.84 & 1.1 & 161 \\
NR/Na+-MMT & 31.1 & 2.6 & 0.68 & 1.3 & 197 \\
NR/O-MMT & 21.5 & 2.5 & 0.96 & 1.0 & 140 \\
\hline
\end{tabular}

*According to Elias (Elias, H. G. In Macromolecules Structure and Properties; Plenum Press: New York, 1977) the mass of the chains between entanglements for the pristine unmasticated-NR is $M_{\mathrm{e}}$ $20100 \mathrm{~g} / \mathrm{mol}$. 


\section{References and Notes}

(1) Bateman, L. The Chemistry and Physics of Rubber-like Substances; MacLaren \& Sons: London, 1963. Roberts, A. D. Natural Rubber Science and Technology; Oxford University Press: Oxford, 1988. Mark, J. E.; Erman, B.; Eirich, F. R. Science and Technology of Rubber; Academic Press: San Diego, 1994. Gent, A. N. Engineering with Rubber, How to Design Rubber Components, Carl Hanser Verlag: Munich, 2001. White, J. R.; De, S. K. Rubber Technologist's Handbook; Rapra Technology: Shawbury, Shrewsbury, Shropshire, 2001.

(2) Tanaka, Y. Rubber Chem. Technol. 2001, 74, 355. Karino, T.; Ikeda, Y.; Yasuda, Y.; Kohjiya, S.; Shibayama, M. Biomacromolecules 2007, 8, 693.

(3) Toki, S.; Sics, I.; Hsiao, B. S.; Amnuaypornsri, S.; Kawahara, S. Strain-induced crystallization in un-vulcanized natural rubbers by synchrotron x-ray study. Submitted to Journal. Amnuaypornsri, S.; Toki, S.; Hsiao, B. S.; Sakdapipanich, J.; Tanaka, Y. Strain-induced crystallization of un-vulcanized natural rubber: effect of proteins and phospholipids. Submitted to Journal.

(4) Flory, P. J. J. Chem. Phys. 1947, 15, 397. Mandelkern, L. Rubber Chem. Technol. 1993, 66, G61. Magill, J. H. Rubber Chem. Technol. 1995, 68, 507. Toki, S.; Fujimaki, T.; Okuyama, M. Polymer $2000,41,5423$.

(5) Takahashi, Y.; Kumano, T. Macromolecules 2004, 37, 4860.

(6) Kraus, G. Reinforcement of Elastomers; Wiley-Interscience: New York, 1965.

(7) Toki, S.; Minouchi, N.; Sics, I.; Hsiao, B. S.; Kohjiya, S. Kautschuk Gummi Kunststoffe 2008, 61, 85.

(8) Vaia, R. A.; Maguirre, J. F. Chem. Mater. 2007, 19, 2736.

(9) For comprehensive reviews on polymer-clay nanocomposites the reader is referred to Giannelis, E. P. Adv. Mater. 1996, 8, 29. Giannelis, E. P.; Krishnamoorti, R.; Manias, E. Adv. Polym. Sci. 1999, 
138, 107. Pinnavaia, T. J.; Beall, G.W. Polymer-Clay Nanocomposites; John Wiley \& Sons: New York 2000. Alexandre, M.; Dubois, P. Mater. Sci. Eng. 2000, 28, 1. Ray, S. S.; Okamoto, M. Prog. Polym. Sci. 2003, 28, 1539. Zhang, Q. H.; Yu, A. B.; Lu (Max), G. Q.; Paul, D. R. J. Nanosci. Nanotech. 2005, 10, 1574. Okada, A.; Usuki, A. Macromol. Mater. Eng. 2006, 291, 1449. Winey, K. I.; Vaia, R. A. MRS Bull. 2007, 32, 314.

(10) Arroyo, M.; López-Manchado, M. A.; Herrero, B. Polymer 2003, 44, 2447. López-Manchado, M. A.; Herrero, B.; Arroyo, M. Polym. Int. 2003, 52, 1070. López-Manchado, M. A.; Herrero, B.; Arroyo, M. Polym. Int. 2004, 53, 1766. López-Manchado, M. A.; Valentín, J. L.; Carretero, J.; Barroso, F.; Arroyo, M. Eur. Polym. J. 2007, 43, 4143.

(11) Vaia, R. A. Mater. Today 2004, 7, 32.

(12) Heinrich, G.; Klüppel, M.; Vilgis, T. A. Current Opinion in Solid State \& Materials Science 2002, 6, 195. Vilgis, T. A. Polymer 2005, 46, 4223.

(13) Wang, M. J. Rubber Chem. Technol. 1998, 71, 520.

(14) Payne, A. R. J. App. Polym. Sci. 1962, 19, 57.

(15) Vu, Y. T.; Mark, J. E.; Pham, H. L.; Engelhardt, M. J. App. Polym. Sci. 2001, 82, 1391.

(16) Meissner, B. J. App. Polym. Sci. 1974, 18, 2483. Vilgis, T. A.; Heinrich, G. Macromolecules 1994, 27, 7849. Karásek, L.; Sumita, M. J. Mater. Sci. 1996, 31, 281. Leblanc, J. L. J. Appl. Polym. Sci. 1997, 66, 2257. Huber, G.; Vilgis, T. A. Eur. Phys. J. B. 1998, 3, 217. Karásek, L.; Meissner, B. J. App. Polym. Sci. 1998, 69, 95. Klüppel, M. Adv. Polym. Sci. 2003, 164, 1. Chervanyov, A. I.; Heinrich, G. J. Chem. Phys. 2006, 125, 084703. Gusev, A. A. Macromolecules 2006, 39, 5960.

(17) Gersappe, D. Phys. Rev. Lett. 2002, 89, 058301. Sheng, N.; Boyce, M. C.; Parks, D. M.; Rutledge, G. C.; Abes, J. I.; Cohen, R. E. Polymer 2004, 45, 487. Shah, D.; Maiti, P.; Jiang, D. D.; Batt, C. A.; 
Giannelis, E. P. Adv. Mater. 2005, 17, 525. Tong, H. Z.; Wen, H. R.; Min, Z. R.; Min, Q. Z.; Yu, L. M. Adv. Mater. 2007, 19, 2667.

(18) Reichert, W. F.; Göritz, D.; Duschl, E. J. Polymer 1993, 34, 1216.

(19) Flory, P.J. Chem. Rev. 1944, 35, 51.

(20) Mark, J. E.; Erman, B. Rubberlike Elasticity A Molecular Primer; Wiley: New York, 1988.

(21) Flory, P. J. Principles of Polymer Chemistry, Cornell University Press: Ithaca, NY, 1953.

(22) Mitchell, J. C.; Meier, D. J. J. Polym. Sci. A 1968, 6, 1689. Tosaka, M.; Senoo, K.; Kohjiya, S.; Ikeda, Y. J. Appl. Phys. 2007, 101, 084909.

(23) Gent, A. N. Trans. Faraday Soc. 1954, 50, 521. Gent, A. N. J. Polym. Sci. 1955, 18, 321.

(24) a) Trabelsi, S.; Albouy, P. A.; Rault, J. Macromolecules 2003, 36, 9093. b) Poompradub, S.; Tosaka, M.; Kohjiya, S.; Ikeda, Y.; Toki, S.; Sics, I.; Hsiao, B. S. J. Appl. Phys. 2005, 97, 103529. c) Rault, J.; Marchal, J.; Judeinstein, P.; Albouy, P. A. Eur. Phys. J. E 2006, 21, 243. d) Rault, J.; Marchal, J.; Judeinstein, P.; Albouy, P. A. Macromolecules 2006, 39, 8356. e) Chenal, J. M.; Gauthier, C.; Chazeau, L.; Guy, L.; Bomal, Y. Polymer 2007, 48, 6893.

(25) Karásek, L.; Sumita, M. J. Mater. Sci. 1996, 31, 281.

(26) Reichert, W. F.; Hopfenmüller, M. K.; Göritz, D. J. Mater. Sci. 1987, 22, 3470.

(27) Carretero-González, J.; Verdejo, R.; Toki, S.; Hsiao, B. S.; Giannelis, E. P.; López-Manchado, M. A. Macromolecules 2008, 41, 2295.

(28) Flory, P. J. J. Chem. Phys. 1950, 18, 108.

(29) http://www.novocontrol.de (Novocontrol Technologies GmbH \& Co. KG., Germany) 
(30) Tosaka, M.; Murakami, S.; Poompradub, S.; Kohjiya, S.; Iheda, Y.; Toki, S.; Sics, I.; Hsiao, B. S. Macromolecules 2004, 37, 3299.

(31) Murakami, S.; Senoo, K.; Toki, S.; Kohjiya, S. Polymer 2002, 43, 2117. Trabelsi, S.; Albouy, P. A.; Raoult, J. Macromolecules 2003, 36, 7624.

(32) Kodama, M.; Kawasaki, Y.; Aoki, H.; Yamamoto, E.; Furukawa, Y. In Recent Research Developments in Chemistry \& Physics of Lipids, 1st ed.; Pandalai S. G. Ed.; Transworld Research Network: Trivandrum, 2003; Vol. 1, pp. 85-98.

(33) Small, D. M. The Physical Chemistry of Lipids: From Alkanes to Phospholipids; Handbook for Lipid Research 4; Plenum Press: New York, 1986; pp. 362-369.

(34) a) Theng, B. K. G. Formation and Properties of Clay-Polymer Complexes; Amsterdam: Elsevier, 1979. b) Lagaly, G. Solid State Ionics 1986, 22, 43. c) Vaia, R. A.; Teukolsky, R. K.; Giannelis, E. P. Chem. Mater. 1994, 6, 1017. d) Xie, W.; Gao, Z.; Pan, W. P.; Hunter, D.; Singh, A.; Vaia, R. A. Chem. Mater. 2001, 13, 2979. e) Osman, M. A.; Ernst, M.; Meier, B. H.; Suter, U. W. J. Phys. Chem B 2002, 106, 653. f) Heinz, H.; Suter, U. W. Angew. Chem. Int. Ed. 2004, 43, 2239. g) Zhu, J.; He, H.; Zhu, L.; Wen, X.; Deng, F. J. Colloid Interf. Sci. 2005, 286, 239. h) Heinz, H.; Koerner, H.; Anderson, K. L.; Vaia, R. A.; Farmer, B. L. Chem. Mater. 2005, 17, 5658. i) He, H.; Ding, Z.; Zhu, J.; Yuan, P.; Xi, Y.; Yang, D.; Frost, R. L. 2005, 53, 287. j) Jacobs, J. D.; Koerner, H.; Heinz, H.; Farmer, B. L.; Mirau, P.; Garrett, P. H.; Vaia, R. A. J. Phys. Chem. B 2006, 110, 20143. k) Heinz, H.; Vaia, R. A.; Krishnamoorti, R.; Farmer, B. L. Chem. Mater. 2007, 19, 59.

(35) Vaia, R. A.; Ishii, H.; Giannelis, E. P. Chem. Mater. 1993, 5, 1694. Vaia, R. A.; Jandt, K. D.; Kramer, E. J.; Giannelis, E. P. Chem. Mater. 1996, 8, 2628.

(36) Stockmayer, W. H.; Baur, M. E. J. Am. Chem. Soc. 1964, 86, 3485. Kremer, F.; Schönhals, A. Broadband Dielectric Spectroscopy; Berlin: Spinger-Verlag, 2003. Strobl, G. The Physics of 
Polymers. Concepts for Understanding their Structures and Behaviour; Berlin: Springer-Verlag, 1997.

(37) Adachi, K.; Kotaka, T. Macromolecules 1984, 17, 120. Adachi, K.; Kotaka, T. Macromolecules 1985, 18, 466. Boese, D.; Kremer, F.; Fetters, L. J. Polymer 1990, 31, 1831.

(38) Adachi, K.; Kotaka, T. Macromolecules 1987, 20, 2018.

(39) Poh, B. T.; Adachi, K.; Kotaka, T. Macromolecules 1987, 20, 2574. Donth, E.; Beiner, M.; Reissig, S.; Korus, J.; Garwe, F.; Vieweg, S.; Kahle, S.; Hempel, E.; Schröter, K. Macromolecules 1996, 29, 6589 .

(40) Calvet, R. Clays and Clays Minerals 1975, 23, 257.

(41) Saalwächter, K.; Herrero, B.; López-Manchado, M. A. Macromolecules 2005, 38, 9650.

(42) Grinberg, F.; Garbarczyk, M.; Kuhn, W. J. Chem. Phys. 1999, 24, 11222.

(43) Toki, S.; Sics, I.; Ran, S.; Liu, L.; Hsiao, B. S.; Murakami, S.; Senoo, K.; Kohjiya, S.; Macromolecules 2002, 35, 6578 .

(44) Treloar, L. R. G. The Physics of Rubber Elasticity. $3^{\text {rd }}$ Edition, Clarendon Press, Oxford, United Kingdom, 1975.

(45) Andrews, E. H.; Owen, P. J.; Singh, A. Rubber Chem. Technol. 1972, 45, 1315. 


\section{"For Table of Contents Use Only"}

\section{Effect of Nanoclay on Natural Rubber Microstructure}

Javier Carretero-González, Haris Retsos, Raquel Verdejo, Shigeyuki Toki, Benjamin S. Hsiao,

Emmanuel P. Giannelis, Miguel A. López-Manchado.
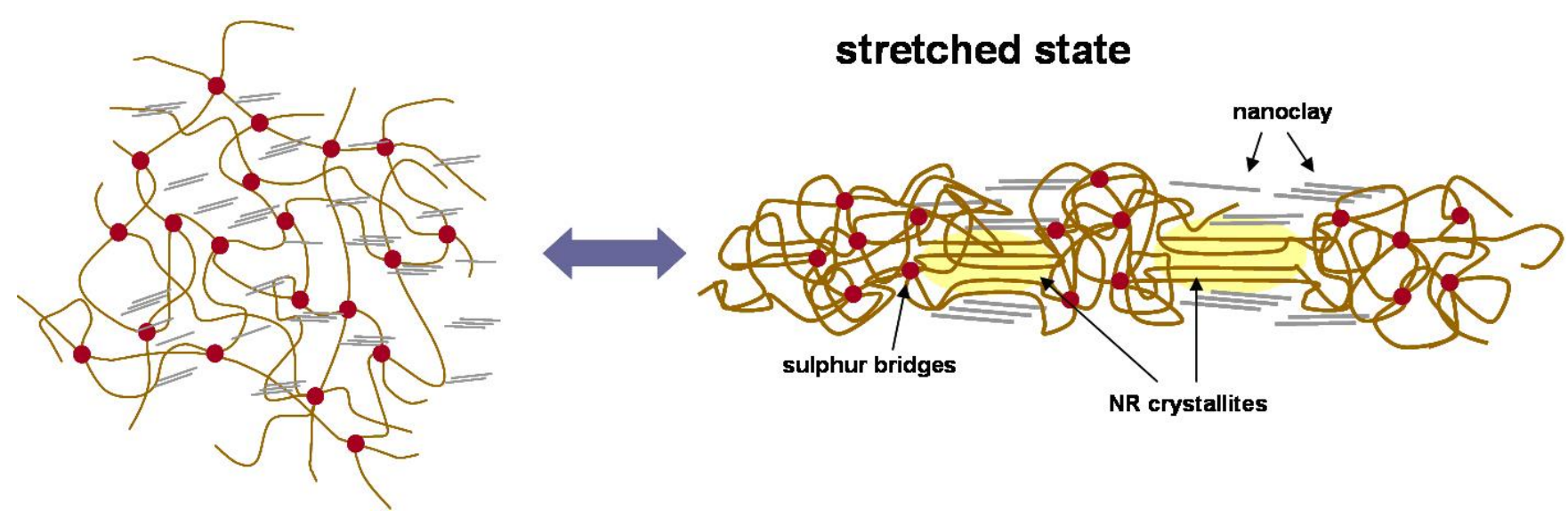